\title{
DIE AARD, STUDIEVELD EN FUNKSIE VAN DIE KRYGSGESKIEDENIS ${ }^{1}$
}

\author{
Kmdt G.E. Visser ${ }^{*}$
}

\section{THE NATURE, SCOPE AND FUNCTION OF MILITARY HISTORY}

As a result of the tremendous impact the military has had on society and vice versa, the scope of military history has become practically as wide as that of history in general.

\begin{abstract}
Military history has both an educational and a practical use. It enables the soldier to see warfare in perspective, to relate it to the times of peace and the societies from which it originated, with the way in which societies determine the nature and extent of wars and the way in which societies are influenced by wars. It makes the soldier aware of the continuity of certain factors in warfare, yet also of the ever-changing nature and character of warfare.

With a knowledge of what others before him have attempted, of what succeeded and what did not, the soldier can tackle the problems of his time with greater insight and perspective. While the study of military history does not bring immediate solutions to contemporary problems or ensure success on the battlefield, it remains the only alternative for personal experience.
\end{abstract}

\section{INLEIDING}

As die historikus vandag die weë van die mens probeer naspeur tot in die skemerlig van die prehistoriese tydperk, is dit opvallend dat wapens haas die enigste oorblyfsels is wat ons aan die wel en wee van die vroegste aardbewoners herinner. Hoewel daar geredeneer kan word dat die ruwe klipbyle en -messe van weleer primêr vir jagdoeleindes gebruik is, ${ }^{2}$ is daar sterk aanduidings dat oorlogvoering van die begin af die aktiwiteite van die mens gedomineer het. ${ }^{3}$ Verskuif ons ons blik van die prehistoriese na die historiese tydperk, dan sê Robert Leckie dat daar in die 5500 jaar opgetekende geskiedenis van die mensdom skaars 230 jaar van vrede was en dat oorlog eerder as vrede dus die "normale" toestand in die menslike samelewing is. ${ }^{4}$ Leckie opper selfs so terloops die moontlikheid dat die oorsprong van die historiese tydperk miskien juis uit oorlogvoering spruit as hy skryf : "It might very well have been that the warrior's desire to perpetuate the glory of his deeds in song and story was the original impetus for written language, the arrival of which is usually considered the beginning of civilized society". 5

Of ons nou saamstem met die opvatting dat oorlog die normale en vrede die abnormale toestand in die menslike samelewing is of nie, dit staan soos ' $n$ paal bo water dat oorlogvoering vanwee sy blote frekwensie ' $n$ prominente plek in die geskiedenis beklee. ' $n$ Franse generaal, $\mathrm{CH}$. de Cossé-Brissac, het in dié verband gesê:

"Professional soldiering deserves its place in history along with man's most important and consuming interests. No other activity has stirred in man such passion, engaged so greatly his moral forces and psychological capacity and devoured so much of his mental and physical energy. We can condemn and regret war, but we cannot

1 Referaat gelewer by 'n Simposium oor Suid-Afrikaanse militêre geskiedskrywing in Bloemfontein op 9-10 Oktober 1992.

2 J. Boudet, director. The Ancient Art of Warfare, 1 : 1300 B.C. - 1650 A.D. : From Ramses to Vauban (London, 1966), 10.

3 J. Boudet, director. The Ancient Art of Warfare, I. 10; J. Terraine. 'What is Military History?'. Military History, 10, 10, 1/105 (Oct. 1982), 433.

4 R. Leckie, Warfare (New York, 1970), xi.

5 R. Leckie. Warfare, 6. 
dismiss the soldier from history" ${ }^{\circ}$

Ten spyte van die sentrale plek wat oorlogvoering in die verlede van die mensdom beklee, word daar baie vrae oor die aard en relevansie van die krygsgeskiedenis gevra. Vrae wat meestal in hierdie verband gevra word, is: "Wat is krygsgeskiedenis?", "Waarom moet ons krygsgeskiedenis bestudeer?", "Vir wie is krygsgeskiedenis van belang?", "Is daar lesse te leer uit die krygsgeskiedenis?" en "Indien daar wel lesse uit die krygsgeskiedenis te leer is, is die lesse van vervloe oorloe hoegenaamd relevant vir moderne oorlogvoering?".

\section{WAT IS KRYGSGESKIEDENIS?}

Daar word gesê dat dit makliker is om geskledenis te skryf as om dit te definieer, ${ }^{7}$ wat sekerlik ook waar is van die krygsgeskiedenis. As ons egter van die tradisionele standpunt uitgaan dat die geskiedeniswetenskap die opgetekende menslike verlede as studieveld het, volg dit logies dat die opgetekende gedeelte van die menslike verlede wat met oorlogvoering te make het, die studieveld van die krygsgeskledenis vorm. ${ }^{8}$ Soos vroeër aangetoon, het oorlogvoering inderdaad ' $n$ belangrike deel van die menslike bestaan uitgemaak lank voordat die skryfkuns teen ongeveer 3500 v.C. ontwikkel is, maar oorlogvoering in daardie tydperk behoort volgens die tradisionele opvatting van die geskiedeniswetenskap tot die voorgeskiedenis of prehistorie en val in die studieveld van die argeoloog. Die vertolking van prehistoriese bronne soos pylpunte, potskerwe en versteende kopbene, vereis vaardighede waaroor die historikus normaalweg nie beskik nie, terwyl sodanige bronne ook nie genoeg inligting vir wetenskaplike geskiedskrywing verskaf nie. Die historikus is op skriftelike bronne aangewese om sy vak op 'n wetenskaplik verantwoordbare grondslag te beoefen. ${ }^{9}$
Om tot ' $n$ sinvolle definisie van krygsgeskiedenis te geraak, moet 'n mens dié begrip volgens die Amerikaanse krygshistorikus, Maurice Matloff, in konteks bestudeer, omdat die definisie van krygsgeskiedenis wissel na gelang van die besondere tydperk wat ter sprake is. In die 18de eeu, voordat die Franse Rewolusie die konsep van "n "volksleer" ("nation in arms") na vore gebring het, voordat oorlogvoering gedemokratiseer geraak het, was oorlogvoering relatief eenvoudig. Die oorlogsteater, gewapende magte en doelwitte van oorlogvoering was beperk. Daarom het die begrip krygsgeskiedenis in daardie tydperk na die geskiedenis van gewapende konflik, veldslae en veldtogte verwys. Die totstandkoming van massaleërs en die invloed van die Industriële Rewolusie het oorlogvoering egter meer omvattend gemaak. Die geleidelike oorskakeling van beperkte na totale oorlogvoering het die impak van oorlogvoering op die gemeenskap progressief laat toeneem. Gedurende die Eerste en Tweede Wêreldoorloë het oorlogvoering nie net die vegtende nasies beïnvloed nie, maar ook dié state wat nie aktief by die oorlog betrokke was nie. Waar oorloe vroeêr formeel deur oorlogsverklarings en vredesverdrae afgebaken is, word dié seremonies sedert die Tweede Wêreldoorlog nie meer nagekom nie, sodat daar nie meer ' $n$ duidelike skeiding tussen tydperke van vrede en oorlog is nie. Daarby het die militere professie sedert die Tweede Wêreldoorlog groot veranderinge ondergaan en is oorlogvoering in die konvensionele sin van die woord lank nie meer die soldaat se enigste funksie nie. In die lae-intensiteit-oorloe van ons tyd is hy ook 'n programbestuurder wat met die bevordering van algemene welvaart en binnelandse rus en vrede gemoeid is. Soos die omvang en invloed van oorlogvoering (en die militêre professie) wyer uitgekring het, het ook die studieveld van die krygsgeskiedenis uitgebrei. ${ }^{10}$

- $\mathrm{CH}$. de Cossé-Brissac. 'Preface', in J. Boudet, director, The Ancient Art of Warfare, I. 8.

7 M. Matloff. 'The Nature of History', in J.E. Jessup. Jr and R.W. Coakley. A Guide to the Study and Use of Military History (Washington, D.C.. 1980). 3.

s B.J. Liebenberg. 'Die Terrein van Geskiedenis', (Presidentsrede gelewer by die dertiende konferensie van die Suid-Afrikaanse Historiese Vereniging by die Universiteit van Suid-Afrika op 22 Januarie 1992). Suid-Afrikaanse Historiese Joernaal, 26. (Mei 1992), 63-64: J. Terraine. 'What is Military History?', 433.

B.J. Liebenberg. 'Die Terrein van Geskiedenis', 64.

10 M. Matloff. 'The Nature and Scope of Military History', in R.F. Weigley, ed, New Dimensions in Military History : An Anthology (San Rafael, 1975), 387-389. 398. 
Hoewel leërs as sosiale instellings histories ontwikkel het met die primêre doel om oorlog te voer, het hulle ook dwarsdeur die geskiedenis in vredestyd 'n betekenisvolle rol as sosiale kragte gespeel. Matloff noem in hierdie verband die bydrae van die Amerikaanse leër op die gebied van die geneeskunde, sanitasie, vloedbeheer, kommunikasie, vervoerdienste en die ingenieurswese, asook in die opwaartse sosiale mobiliteit van minderbevoorregte groepe. So het die Amerikaanse leër byvoorbeeld teen die helfte van die vorige eeu deur die opname van Europese immigante in sy geledere ' $n$ betekenisvolle rol in hul akkulturasie in die Amerikaanse gemeenskap gespeel. Dit was ook die Amerikaanse leër wat in die vyftigeren sestigerjare van hierdie eeu die toon aangegee het met die inskakeling van die Negers op alle vlakke van die samelewing." In ons ele geskiedenis hoef ons maar net na gebeure soos die Laingsburgvloed, welsynsdienste in die agtergeblewe gemeenskappe en die onlangse mediaverslae oor die SA Geneeskundige Diens se baanbrekerswerk op die terrein van amputasietegnieke te kyk, om te sien watter belangrike sosiale rol die Suid-Afrikaanse Weermag in vredestyd in die gemeenskap speel. Soos die Amerikaanse leër in die geval van die Negers, het die Suid-Afrikaanse Weermag ook die voortou geneem met die inskakeling van lede van die swart, bruin en Indiërgemeenskappe by ons sosiale instellings.

Die krygshistorikus is dus vandag deeglik daarvan bewus dat oorloè nie in ' $\mathrm{n}$ vakuum gevoer word nie, maar dat dit die funksie van groter historiese kragte is. Militêre mag is bloot ' $\mathrm{n}$ middel om politieke beleid uit te voer en daarom is oorlog ' $n$ integerende deel van ' $n$ groter geheel. Die uitkoms van oorloë word nie net deur die moed en vaardigheid van soldate bepaal nie, maar ook deur die aard en organisasie van die gemeenskappe in wie se diens hulle staan. Daarom is elke aspek van 'n staat se sosiale, ekonomiese en politieke orde wat ' $n$ invloed op sy militêre mag uitoefen, vir die krygsgeskiedenis van belang ${ }^{12}$ en lê die hedendaagse benadering tot dié dissipline groot klem op die onderlinge verband tussen oorlogvoering en die gemeenskap. Moderne krygsgeskiedenis het dus te make met die wyse waarop state vir oorlog voorberei, hoe hulle oorloë voer en beëindig, hoe die voorbereiding vir en die voer van oorloẹ gemeenskappe beïnvloed en hoe state die vredestydse funksies van weermagte bepaal en reguleer. Die studieveld van die krygsgeskiedenis is derhalwe vandag byna net so wyd as dié van die geskiedeniswetenskap in die algemeen. ${ }^{13}$

\section{TIPES KRYGSGESKIEDENIS}

Krygsgeskiedenis kan breedweg in drie kategoriee ingedeel word, te wete, operasioneel, administratief en tegnies, en die militêr en die gemeenskap. Operasionele krygsgeskiedenis is waarskynlik die bekendste en mees algemene vorm van krygsgeskiedenis en handel oor die verloop van gevegte, veldtogte en oorloë. Dit omvat ook aspekte soos militêre strategle, taktiek, logistiek en leierskap. Krygeskiedenis van ' $n$ administratiewe en tegniese aard fokus op die algemene funksionele en professionele aktiwiteite van weermagte in vredes- en oorlogstyd en behandel temas soos militêre doktrine, organisatorise strukture, werwing en opleiding van mannekrag, asook wapenontwikkeling. Die onderafdeling van die krygsgeskiedenis wat die militêr en die gemeenskap as studieveld het, en tans wêreldwyd hoë prioriteit geniet, neem alle militêre aangeleenthede in tye van vrede en oorlog onder die loep. Dit hanteer onder meer nasionale strategie en omsluit die verhouding tussen militêre, sosiale, politieke, ekonomiese en sielkundige faktore op nasionale vlak; dit bestudeer institusionele probleme en ontwikkelings en ondersoek die verhouding tussen burgerlike en militêre gesag. ${ }^{14}$

"M. Matloff. 'The Nature and Scope of Military History', 390-391.

12 M. Blumenson. 'Why Military History? : To Analyze the Past, Discover the Present', Army, (Jan. 1975), 35: W.F. Craven. 'Why Military History?', in H.R. Borowski, ed.. The Harmon Memorial Lectures in Military History, 1959-1987 (Washington, D.C.. 1988), 12, 14-15.

is T.E. Griess, 'A Perspective on Military History', in J.E. Jessup. Jr and R.W. Coakley. A Guide to the Study and Use of Military History (Washington, D.C.. 1980), 31: M. Blumenson. 'Why Military History?', 34-36.

14 T.E. Griess. 'A Perspective on Military History'. 31. 
Dit spreek vanself dat bogenoemde drie kategorieë van krygsgeskiedenis nie onderling uitsluitend is nie. Hoewel 'n bepaalde stuk geskiedskrywing sterk na een van die drie kategorieë mag oorhel, sal dit ook elemente van die ander twee vertoon. ${ }^{15}$ 'n Eenheidsgeskiedenis kan byvoorbeeld ' $n$ sterk operasionele inslag hê, maar moet uiteraard ook aandag skenk aan administratiewe sake soos organisasle en opleiding, terwyl die interaksie tussen die betrokke eenheid en die gemeenskap waarbinne hy opereer, ook van belang is.

\section{DIE FUNKSIE V.AN DIE KRYGSGESKIEDENIS}

Daar word dikwels gesê dat die krygsgeskiedenis net vir die soldaat van belang is, maar as ' $n$ mens die geweldige impak van die militêr op die gemeenskap in vredes-, sowel as oorlogstyd in aanmerking neem, is dit duidelik dat so 'n stelling op wankelrige fondamente berus. Daarbenewens hou baie kontemporêre vraagstukke op een of ander wyse met militêre mag verband, sodat die krysgeskiedenis vandag vir die burgerlike van net soveel belang as vir die militêr is. ${ }^{16}$

Die funksie van krygsgeskiedenis is, net soos dié van die geskiedeniswetenskap in die algemeen, om die verlede te rekonstrueer en in die lig van die hede te verklaar. Ons onvermoë om gebeure in die hede te verstaan, spruit dikwels uit ' $n$ gebrek aan perspektief. 'n Studie van die geskiedenis bring insig in die verlede mee, wat ons help om die hede beter te verstaan. Die hede is immers deel van 'n ontwikkelingsproses, 'n verloop van gebeure wat sy oorsprong in die verlede het, sodat ons ' $n$ gesonder oordeel oor die vraagstukke van ons tyd kan vel as ons hulle in hul historiese konteks begryp. Om dié rede soek die historikus na sin en betekenis in die verlede, na ooreenkomste en samehang, na patrone en tendense in die verloop van gebeure, na kontinuïteit tussen verlede en hede, maar ook na faktore wat gevestigde of waargenome patrone in die verloop van gebeure onderbreek. ${ }^{17}$

Die soldaat heg tradisioneel ' $n$ praktiese nutswaarde aan 'n studie van die krygsgeskiedenis, terwyl akademici meer klem op die opvoedkundige waarde daarvan lê. ${ }^{18}$ Krygshistorici met ervaring as professionele soldate vind dit doodnatuurlik dat krygsgeskiedenis ' $n$ praktiese nutwaarde kan hê. Historici wat die terrein van die krygsgeskiedenis vanuit die akademiese wêreld betree, staan egter dikwels skepties tenoor so 'n benadering. Dié toedrag van sake is volgens die bekende Britse krygshistorikus, Michael Howard, dikwels te wyte aan ' $n$ bepaalde vrees in sekere akademiese kringe, wat krygsgeskiedenis as 'n teelarde vir militarisme beskou, dat die hoofdoel daarvan propaganda en "mite-makery" ("myth-making") is. Hierdie opvatting van die krysgeskiedenis is nie heeltemal ongegrond nie. Historici het in die verlede dikwels deur middel van die versigtige seleksie en interpretasie ' $n$ beeld van die verlede geskep wat daarop gemik was om sekere emosies en opvattings te bevorder, byvoorbeeld om nasionalisme aan te wakker of steun vir 'n politieke owerheid te werf. Dit is dikwels in totalitêre state moelik of selfs onmoontlik om enige ander tipe geskiedenis te skryf. ${ }^{19}$

Hierdie selektiewe en heroïse voorstelling van die verlede het, volgens Howard, met bepaalde voorbehoude, ook aanvaarbare gebruike in demokratiese gemeenskappe. Eenheidsgeskiedskrywers beklemtoon byvoorbeeld dikwels die glansryke episodes in hul geskiedenis en gee weinig aandag aan minder vleiende gebeure, ten einde die indruk te skep dat hul eenhede in veral die nabye verlede, altyd effektief en heldhaftig opgetree het. Dit word sonder enige kwade bedoe-

15 T.E. Griess. 'A Perspective on Military History', 31.

10 J. Luvaas, 'Military History: An Academic Historian's Point of View', in R.F. Weigley, ed, New Dimensions in Military History: An Anthology (San Rafael, 1975), 35.

17 M. Blumenson. 'Why Military History?', 33, 37: F.J. Du T. Spies. 'Leemtes in die Suid-Afrikaanse Geskiedskrywing', Suid-Afrikaanse Historiese Joernaal, 3 (Nov 1971), 92; J. Luvaas. 'Military History'. 24.35.

18 T.E. Griess. 'A Perspective on Military History' . 31.

19 M. Howard. 'The Use and Abuse of Military History' (Lecture given at the Royal United Services Institution on 18 October 1961), Journal of the Royal United Services Institution. 107. (Feb. 1962), 4. 
lings gedoen en is daarop gemik om die esprit de corps aan te wakker en die eenheidsmoreel hoog te hou, om soldate te motiveer om die "trotse tradisie" van hul eenheid gestand te doen. Die tendens om struikelblokke en ontbering op die slagveld te beklemtoon, kan soldate weer help om vinniger aan te pas, deurdat hulle weet dat hul voorgangers soortgelyke of moeiliker omstandighede te bowe gekom het. ${ }^{20}$

Hoewel dit volgens Howard nie 'n doodsonde is om krygsgeskiedeins op hierdie wyse aan te wend nie, maan hy egter dat dit belangrik is dat die gebeure waarheidsgetrou weergegee moet word, omdat inspirasie in ontnugtering kan omsit as die geskiedenis verwring of té romanties aangebied word. Die jong soldaat kan dit byvoorbeeld tydens sy vuurdoop onmoontlik vind om die gaping tussen die romantiese beeld van oorlogvoering wat vir hom opgetower is en die wrede werklikheid van die slagveld te oorbrug die gaping tussen hoe hy, sy makkers en hul leiers veronderstel is om op te tree en hoe hulle werklik optree; hy mag dit dus ontmoontlik vind om lafhartigheid, vrees, uitputting en die menslike ellende op die slagveld te verwerk. ${ }^{21}$

Die krygsgeskiedenis is waarskynlik onder groter druk as enige ander vorm van geskiedenis om 'n didaktiese funksie te vervul. ${ }^{22}$ Generaal John M. Schofield het in 1899 die doel van historiese studie beskryf as synde'... to reduce the chances of war to the minimum; to bring it as nearly as possible within the domain of exact science. ${ }^{\prime 23}$ Gen-maj Sir William Napier het op sy beurt by geleentheid geskryf : War , however adorned by splendid strokes of skill, is commonly a series of errors and accidents.' ${ }^{24}$ Die historikus Peter Parish, het met betrekking tot die toepassing van nuwe tegnologie op oorlogvoering bygevoeg 'New capacity meant new complexity; new methods of making war meant new ways of making mistakes.'25 Die soldaat wil dus die geskiedenis benut om lesse uit die verlede te leer. om die onsekerheid op die slagveld te verminder en hom beter vir sy professie te bekwaam.

Die soldaat se hunkering na inspirasie uit die verlede spruit uit die feit dat dat die offisier hom in die onbenydenswaardige posisie bevind dat sy professionele bedrewendheid inderwaarheid deur die aard van sy beroep self beperk word. Hy kan nie sy primêre beroep, naamlik oorlogvoering, daagliks beoefen nie, omdat geen staat permanent in oorlog gedompel is nie. Waneer hy egter opgeroep word om oorlog te voer, help hy om die lotsbestemming van nasies en state te bepaal. ${ }^{26}$ Dit is derhalwe belangrik dat die offisier hom in vredestyd so goed as moontlik op sy taak moet voorberei. Om sy gebrek aan persoonlike ervaring op die slagveld vanweë die afwesigheid van oorloe te oorkom, word hy dus feitlik verplig om hom tot ' $n$ studie van die krygsgeskiedenis te wend om uit die ervaring van ander te leer. ${ }^{27}$ Die krygsgeskiedenis stel hom in staat om 'n groot verskeidenheid operasies, wat onder verskillende omstandighede gevoer is, te ontleed en uit die suksesse en mislukkings van die verlede te leer. ${ }^{28}$

Offisiere wat weet wat in die verlede probeer is, onder watter omstandighede dit geskied het en wat die resultaat daarvan was, sal minder genee wees om die foute van die verlede te herhaal of hulpeloos in die donker rond te tas wanneer hulle met ' $n$ probleem gekonfronteer word. ${ }^{29}$ Historiese

20 M. Howard. 'The Use and Abuse of Military History', 4 - 5: T.E Griess, 'A Perspective on Military History'. 34.

21 M. Howard, 'The Use and Abuse of Military History', 4 -5: T.E. Griess, 'A Perspective on Military History', 34.

22 J. Luvaas, 'Military History', 22.

23 J.F. Votaw. 'An Approach to the Study of Military History', in J.E. Jessup. Jr and R.W. Coakley. A Guide to the Study and Use of Military History' (Washington. D.C.. 1980), 55.

$24 \mathrm{~J}$. Terraine. 'What is Military History?', 437.

$25 \mathrm{~J}$. Terraine, 'What is Military History?', 437.

20 H.R. Winton and H.H. Lau. 'History and the Professional Soldier'. Military Review, LIV, 4, (Apr. 1974$), 38$.

27 M. Howard. 'The Use and Abuse of Military History', 7.

28 T.E. Griess, A Perspective on Military History', 32: M. Matloff, 'The Nature of History'. in J.E. Jessup. Jr and R.W. Coakley. A Guide to the Study and Use of Military History' (Washington D.C. 1980), 17.

29 T.E. Griess. 'A Perspective on Military History', 32. 
studie verskaf naamlik perspektief op huidige militêre vraagstukke, bevorder die offisier se analitiese denke, verskerp sy oordeel, verbreed sy horison en voorsien hom van ' $n$ verwysingsraamwerk, wat hom in staat stel om gesonde doktrines te formuleer. ${ }^{30}$ Deur die krygsgeskiedenis versigtig en objektief te ontleed, kan hy ' $n$ begrip vir die ewolusie van oorlogvoering verkry en sekere breë beginsels aflei wat normaalweg met sukses op die slagveld toegepas kan word, byvoorbeeld dat offensiewe optrede en konsentrasie van mag op die beslissende punt gewoonlik tot sukses lei en dat deeglike opleiding dikwels 'n vyandelike oorwig in getalle kan neutraliseer. Die beginsels van oorlog wat J.F.C. Fuller op grond van ' $n$ deeglike studie van die krygsgeskiedenis geformuleer het, word vandag feitelik dwarsoor die wêreld as doktrine aanvaar. Die geskiedenis het egter ook bewys dat sodanige beginsels dikwels, soms doelbewus en om spesifieke redes, verbreek word; dat dit bulgsaam toegepas moet word en nie onverbiddelike reëls is waaraan die soldaat ten alle koste moet vasklou nie. ${ }^{31}$

Sommige kritici beweer dat die krygsgeskiedenis weinig waarde het, aangesien vorige oorloë vanweë veranderde omstandighede, wapentuig, ens, vandag nie meer relevant is nie. Hulle glo dat die belangrikste veranderlike in oorlogvoering - die mens self - so onvoorspelbaar en irrassioneel is, dat dit onmoontlik is om op 'lesse' uit die verlede staat te maak om kontemporêre probleme op te los. Hulle standpunt is dat indien die geskiedenis ons enigiets geleer het, dan is dit 'dont prepare to fight the last war'. ${ }^{32}$ Dit is egter ' $n$ baie eng en gevaarlike standpunt, omdat ons nooit heeltemal aan die verlede kan ontsnap nie. Hoewel daar inderdaad wesentlike historiese verskille tussen oorloe is, is daar ook groot ooreenkomste tussen hulle en is daar sekere fundamentele beginsels waaraan selfs die verloop van eeue niks verander nie. Die bekende Chi- nese militêre denker, Sun Tzu, het sy "Art of War" reeds teen ongeveer 500 v.C. geskryf, maar baie van die beginsels wat hy neergelê het, hou vandag nog water. Alhoewel die strydwa lank reeds van die slagveld verdwyn het en wapens ingrypend verander het, kan sy denke nog met vrug op moderne oorlogvoering toegepas word, juis omdat hy hom met grondbeginsels, soos die invloed van politiek en die menslike natuur op militêre operasies, besig gehou het. ${ }^{33}$ Die beroemde militêre denker, Carl von Clausewitz, het egter tereg daarop gewys dat die mees resente krygsgeskiedeins vanselfsprekend die beste bron vir historiese voorbeelde of sogenaamde lesse is, omdat dit dikwels vollediger en meer akkuraat beskryf is as wat die geval met ouer krygsgeskiedenis is. Oorloe uit die onlangse verlede vertoon ook groter ooreenkomste met hedendaagse oorlogvoering. ${ }^{34}$

Die kritiek van diegene wat skepties teenoor die waarde van die krygsgeskiedenis staan, is nie totaal ongegrond nie, omdat die soldaat dikwels in die strik trap om na direkte lesse in die verlede te soek, wat sonder uitsondering tot sukses op die slagveld sal lel. Dit het dikwels ' $n$ oppervlakkige, selektiewe studie van die krygsgeskiedenis tot gevolg, waar die persoon probeer om ' $n$ voorafbepaalde teorie sogenaamd deur middel van historiese voorbeelde te "bewys" - hy weet reeds wat hy wil vind en selekteer dan slegs dié feite wat sy argumente "pas". 35

Net soos die soldaat egter die eienskappe en vermoëns van 'n nuwe wapen deeglik moet bestudeer voordat hy sinvolle beslulte oor die aanwending daarvan kan neem, moet hy ook die aard van die krygsgeskiedenis ondersoek, alvorens hy probeer om dit in diens van sy professie te stel. Hy moet die potensiaal, sowel as die beperkings daarvan begryp. Hy moet wel deeglik daarvan bewus wees dat elke gebeur-tenis uniek is en dat die geskiedenis homself nie herhaal nie.

30 J.F Votaw, An Approach to the Study of Military History', 50.

32 F.F. Marvin. 'Using History in Military Decision Making'. Military Review. LXVIII. 6. (Jun. 1998), 23.

33 T.R. Phillips. 'Introduction', in Sun Tzu Wu, The Art of War, translated from the Chinese by L. Giles (Harrisburg. 1944), 9

34 C. von Clausewitz. On War, edited and translated by M. Howard and P. Paret (Princeton, 1976 ), 173.

35 J. Luvaas. 'Military History', 24 -. 25-. 28 -29. 34: T.E. Griess, 'A Perspective on Military History', 33 - 34. 
Daarby moet hy begryp dat die geskiedenis ' $n$ poging deur die historikus is om die verlede op grond van die beskikbare feite te rekonstrueer, maar dat alle feite nie altyd beskikbaar is nie, terwyl dié wat wel beskikbaar is, dikwels so oorvloedig is, dat die historikus nie alles kan gebruik nie. Hy selekteer slegs dié wat volgens sy persoonlike oordeel - wat beinvloed word deur sy ele ver-lede, hede en toekomsverwagting - belangrik is. ${ }^{36} \mathrm{Die}$ krygsgeskiedenis, soos enige ander vorm van geskiedenis, verloor daarby met verloop van tyd sekere klein detail, wat daartoe lei dat slegs die hooftrekke uiteindelik behoue bly en dit dan die gevaar loop om uit verband geruk te word. $^{37}$ Krygsgeskiedenis kan boonop maklik skeefgetrek word deur nasionale trots, 'n oormaat van entoesiasme, onkunde of sterk vooroordele. Die soldaat wat krygsgeskiedenis skryf, mag dit moontlik inkleur om reputasies te beskerm of ou lojaliteite in stand te hou. Siviele historici beskik aan die ander kant dikwels nie oor die nodige militêre ervaring of tegniese kennis om reg aan bepaalde vorme van krygsgeskiedenis te laat geskied nie. ${ }^{38}$

'n Grondige kennis van die krygsgeskiedenis is geen waarborg vir sukses op die slagveld nie, omdat ' $n$ studie van die krygsgeskiedeins 'n opvoedingsproses is en nie ' $n$ opleidingsprogram nie. Historiese gebeure kan nie sonder meer aan huidige maatstawwe gemeet word nie. Gebeure uit die verlede mag dikwels groot ooreenkomste met gebeurtenisse in die hede vertoon, maar hulle is nooit presies eenders nie en daarom kan die geskiedenis nooit klinkklare oplossings vir kontemporêre probleme bied nie. ${ }^{39}$ Wapens verander, tegnologie gaan vooruit en die mens se motivering om te veg, wissel, sodat ' $n$ vorige oorlog totaal irrelevant vir die daaropvolgende een mag wees. Howard waarsku hierteen as hy sê : "..the differences brought about between one war and another by social or technological changes are immense, and an unintelligent study of military history which does not take adequate account of these changes may quite easily be more dangerous than no study at all. Like the statesman, the soldier has to steer between the danger of repeating the errors of the past because he is ignorant that they have been made, and the danger of remaining bound by theories deduced from past history although changes in conditions have rendered these theories obsolete." 40

Die offisier wat inspirasie uit die verlede wil put, moet altyd in gedagte hou dat die lesse van die verlede gewoonlik nie baie duidelik is nie en dat dit dikwels duideliker in die negatief is, dit wil sê. dat die geskiedenis ons makliker leer wat ons nie moet doen nie, as wat dit ons leer wat ons moet doen. ${ }^{41}$ ' $n$ Oormaat van vetroue in die historiese presedent hou natuurlik ook die gevaar in dat die offisier nuwe metodes en benaderings sonder meer kan verwerp. bloot omdat die sukses daarvan nie histories bewys is nie. ${ }^{42}$

Howard waarsku dat die offiser wat krygsgeskiedenis as ' $n$ riglyn vir sy professie wil bestudeer, dit in wydte, diepte en konteks moet doen om die slaggate van dié praktyk te vermy. Studie in wydte beteken dat die ontwikkeling of ewolusie van oorlogvoering oor ' $n$ lang tyd bestudeer moet word. Langs dié weg word dit duidelik wat oor tyd in oorlogvoering verander het en kan daar terselfdertyd afgelei word wat nie verander het nie. Studie in diepte beteken dat ' $n$ bepaalde veldtog deeglik bestudeer moet word, nie net deur middel van amptelike geskiedenisse nie, maar ook aan die hand van briewe, herinneringe, dagboeke en selfs verbeeldingryke literatuur, ten einde agter die volle waar-

\footnotetext{
36 H.R. Winton and H.H. Lau. 'History and the Professional Soldier', 32; M. Matloff. 'The Nature of History', 15 -16: M. Blumenson, 'Why Military History?', 37.

37 C. von Clausewitz, On War, 173.

38 J. Luvaas, 'Military History', 34 -35.

39 T.E. Griess, 'A Perspective on Military History'. 33; W.F. Craven. 'Why Military History?', 15 -16.

40 M. Howard. 'The Use and Abuse of Military History" 7.

41 M. Matloff. 'The Nature and Scope of Military History', 402; M. Howard' 'The Use and Abuse of Military History'. 7.

42 H.R. Winton and H.H. Lau, 'History and the Proffesional Soldier', 38.
} 
heid te kom. Die offisier moet deur die orde dring wat die historikus deur sy seleksie van feite geskep het en die chaos en verwarring van die slagveld ervaar; hy moet vasstel watter rol beplanning, bekwaamheid en moed aan die een kant en suiwer geluk aan die ander kant gespeel het. Slegs langs dié weg kan diegene wat self geen praktiese ervaring van oorlogvoering het nie agterkom hoe oorlog regtig is, wat werklik op die slagveld gebeur. Studie in konteks beteken dat oorloë bestu-deer moet word teen die agtergrond van die gemeenskappe wat dit voer. Die offisier kan 'n bepaalde oorlog slegs na. behore verstaan as hy die aard van die gemeenskappe wat dit gevoer het, begryp. Die oorsprong van nederlaag of oorwinning lê dikwels nie op die slagveld self nie, maar in sosiale, politieke en ekonomiese faktore wat die aard van die gewapende magte en die wyse waarop die generaals die oorlog voer, bepaal. Sonder kennis van die breër agtergrond van militêre operasies kan die offisier maklik verkeerde afleidings met betrekking tot die aard van sodanige operasies en die redes vir hul sukses of mislukking maak. ${ }^{43}$

Von Clausewitz het in verband met die benutting van krygsgeskiedenis om die kuns van oorlogvoering te bemeester, gesê :

"To teach the art of war entirely by historical examples... would be an achievement of the utmost value; but it would be more than the work of a lifetime : anyone who set out to do it would first have to equip himself with a thorough personal experience of war."

"Anyone who feels the urge to undertake such a task must dedicate himself for his labours as he would prepare for a pilgrimage to distant lands. He must spare no time or effort, fear no earthly power or rank, and rise above his own vanity, or false modesty in order to tell, in accordance with the expression of the Code Napoleon, the truth, the whole truth, and nothing but the truth." 44

\section{SAMEVATTING}

Opsommenderwys kan ons sê dat die studieveld van die krygsgeskiedenis vanweë die geweldige impak van die militêr op die gemeenskap en andersom, feitlik net so wyd is as dié van die geskiedenis in die algemeen. Die krygsgeskiedenis het beide ' $n$ opvoedkundige en ' $n$ praktiese nutswaarde. Dit stel die soldaat in staat om oorlogvoering in perspektief te sien, om dit in verband te bring met die vredestye en samelewings waaruit dit ontspring, met die wyse waarop samelewings die aard en omvang van oorloë bepaal en die wyse waarop samelewings deur oorloë beïnvloed word. Dit maak die soldaat bewus van die kontinuitteit van sekere faktore in oorlogvoering, maar ook van die immer veranderende aard en karakter daarvan. Op grond van sy kennis van wat andere voor hom probeer het, van wat geslaag en wat misluk het, kan die soldaat die probleme van sy tyd met groter insig en perspektief aanpak. 'n Studie van die krygsgeskiedenis bring nie direkte oplossings vir kontemporêre probleme nie en kan nie sukses op die slagveld verseker nie, maar dit is die enigste alternatief vir persoonlike ervaring. Die ware nut van geskiedenis, hetsy burgerlik of militêr, lê nie daarin om die leser slim te maak vir die volgende keer nie, maar om hom vir altyd wys te maak. Dit sal egter die offisier loon om altyd die stelling in gedagte te hou wat 'n Duitse skrywer 200 jaar gelede gemaak het: 'A book (even a good book) is a mirror: when a monkey looks in, no apostle can look out.' ${ }^{\prime 4}$

"Kmat G.E. Visser, MA is tans die hoof van die Departement Krygsgeskiedenis aan die Militêre Akademie, Saldanha.

43 M. Howard. 'The Use and Abuse of Military History', 7.

44 C. von Clausewitz, On War, 174.

45 Soos aangehaal in J. Luvaas, 'Military History', 36. 